\title{
ON PROTOSTEGA, THE SYSTEMATIC POSITION OF DERMOCHELYS, AND THE MORPHOGENY OF THE CHELONIAN CARAPACE AND PLASTRON.
}

O. P. HAY.

THE structure and relationships of the genus of fossil turtles known as Protostega are being gradually determined. Important additions to our knowledge regarding it have been made recently by .Dr. E. C. Case $^{1}$ and Mr. G. R. Wieland. ${ }^{2}$ The former describes and figures in an excellent way the plastron, the skull, the shoulder girdle, and the limbs ; and discusses at length the relationships to the other Testudines. Mr. Wieland supplies needed information regarding the ribs and the existence of neuralia. He regards the form which he describes as a new genus, which he calls Archelon, but it will be generally agreed, I think, that it is not distinct from Protostega.

One of the most important discoveries made by Case is the arrangement of the xiphiplastrals. When I wrote my paper ${ }^{3}$ on the portion of the plastron of this animal then in my hands, I assumed that the xiphiplastrals had essentially the same form and dimensions as in the modern genus Thalassochelys. Case finds that, on the contrary, immediately after these plastral elements have freed themselves from the hypoplastrals they sharply curve toward the mid-line and come into contact. The length of the plastron is thus much reduced. Dr. Case also concludes that the epiplastrals must have been much shorter than they are in Thalassochelys, and that the entoplastron was probably wanting. From this condition of the plastron Case concludes that my estimate of the size of Protostega was much

1 Journ. of Morphology, vol. xiv, pp. 21-55, Pls. IV-VI.

2 Amer. Journ. Science [4], vol. ii, pp. 399-4I 2, Pl. VI, and 19 text-figures.

${ }^{3}$ Field Columbian Museum Pubs., Zoology, vol. i, pp. 57-62, Pls. IV, V. 
too great, his own calculation making the total length $\mathbf{2 . 2 7 3}$ meters, as against my own estimate of 3.92 meters - a very considerable difference.

However, I do not believe that Case's conclusion necessarily follows from his premises. My estimate was primarily based on the distance from the bottom of the excavation in the hypoplastron for the fore limb to the excavation in the hypoplastron for the hind limb. It seems to me highly probable that these borders of the plastron could not have approached the corresponding limbs of Protostega more closely than they do. in Thalassochelys and yet leave the limbs free to make their movements. The limbs, then, must have been as far apart as they would be in a Thalassochelys whose plastron had the corresponding measure equal. Hence any shortening of the body must have been effected in front of the fore limb and behind the posterior limbs. This would necessitate the shortening of the anterior dorsal and the anterior caudal vertebræ; and of this we have no proof. The dimensions of the various plastral elements are extremely variable in the various genera of turtles ; and it hardly follows that, because the xiphiplastrals are very short, the body of the animal is correspondingly curtailed. The estimate of the length made by Wieland, based on his apparently quite perfect carapace, is not greatly less than my own estimate.

I wish here to make a remark on the genus Atlantochelys of Agassiz. It has been thought that it is identical with Protostega of Cope ; but a comparison of Leidy's figure ${ }^{1}$ of the humerus, on which the name was based with that of Protostega, shows that the two genera are very distinct. The humerus of Atlantochelys contracts below the tuberosities into a much more slender shaft than does Protostega. The humerus of $A t$ lantochelys mortoni resembles not distantly that of Lytoloma, as figured by Dollo. ${ }^{2}$

It was the judgment of Baur, ${ }^{3}$ also, that Atlantochelys is different from Protostega. Cope's $P$. neptunia is merely a

1 Cretaceous Reptiles, U. S., Pl. VIIII, Figs. 3-5.

2 Geol. Mag. [3], vol. v, p. 266.

3 Biolog. Centralblatt, Bd. ix, p. I89. 
synonym of Atlantochelys mortoni, the latter name dating from time of Leidy's figure and description, I865.

In his discussion of the relationships of Protostega to the other Testudines, Case succeeds completely, in my estimation, in proving that the genus under consideration belongs near the Cheloniidæ. Many authors have assigned to it definitely a position among the Dermochelyidæ; but this disposition of it was doubtless due to Cope's error in regarding the plastral plates as portions of the carapace.

Case also endeavors to prove that Protostega is not distantly related to Dermochelys ; that it is, in fact, "a distinctly intermediate form" between Dermochelys and the Cheloniidæ. Dermochelys is, therefore, not worthy of being made the foundation of a distinct suborder, the Athecæ of Cope, but is a member of the superfamily Chelonioidea.

As anatomists are aware, the late Dr. Baur strenuously opposed the proposal to remove Dermochelys far from the company of the other sea turtles. Like Dr. Case, he regarded it as having been derived from the Cheloniidæ, differing from the others in having become more highly specialized for aquatic life.

Baur's arguments had evident effect on his antagonists ; and it will doubtless be admitted by all that he and Case have valiantly defended their position. Now that Protostega has been definitely shown to belong near the Cheloniidæ, many will, no doubt, be inclined to believe that the defended position is unassailable. Notwithstanding all this, I have not been able to divest myself of the feeling that Dermochelys is not to be admitted into the same suborder as the other living sea turtles. And here I recall the words of Van Bemmelen, who felt strongly the force of the arguments employed by the opponents of Baur, but found himself compelled to accept the views of the latter.

As regards Protostega, it appears to me that Case's investigations show conclusively that it has no special relationships to Dermochelys. It is in no important sense an intermediate form; and Case has not so regarded it in his scheme showing lines of descent. 
I shall not enter into any extended discussion of those structures which Dermochelys possesses in common with the other sea turtles. Most of them have already received consideration from Baur, Dollo, Boulenger, Van Bemmelen, and Case. Some of these common characters may be attributed to inheritance from a common remote ancestor; such are, for illustration, the wide separation of the pterygoids seen in both Protostega and Dermochelys, and the roofed-in condition of the temporal region found in Dermochelys and the Cheloniidæ. Other characters possessed in common may be due to convergence, resulting from similarity of habits, movements, etc. I would include in this category the presence of an articulation between the eighth cervical and the nuchal, the plane surfaces of articulation between the sixth and seventh cervicals, and the more or less reduced condition of the carapace and plastron. Probably the surfaces joining the sixth and seventh cervicals are plane for the same reason that they are plane between the various dorsal vertebræ; namely, this articulation is one situated where there is only slight movement, lying, as it does, between two curves in opposite directions.

But whatever may be the conclusions reached concerning the other points in the anatomy of Dermochelys, its singular dorsal and ventral shields form one of the most striking characters of the animal, the one about which there has been the most contention, and the one which probably furnishes the key to the situation. The condition and mode of origin of this carapace were the most difficult matters for Baur to explain ; and regarding its morphogeny he changed his mind more than once. At the time the discussion was going on between himself and Dollo and Boulenger, Baur took the position that the carapace of Dermochelys had been derived from that of its Chelonioid ancestors through delamination of the layer of membrane bone from the ribs, and the dissolution of this into polygonal pieces. Later he came to the conclusion that the membrane bone of the carapace of Dermochelys had become wholly, or nearly wholly, reduced, and that the layer of mosaic-like pieces was of secondary origin, an entirely new development. Case adopts this later expressed opinion. 
This view, however, is not without difficulties of its own. Dollo and Seeley have both referred to the fact that the dermal plastron of Dermochelys is not complete; that is, the bony mosaic is deficient in the spaces between the longitudinal keels of the plastron. Shall we now regard this condition as a stage on the way toward a complete plastron; or shall we hold that the complete plastron was once possessed and that the present condition was due to reduction? The former way of looking at the matter is opposed to the fact that Dollo and Seeley concluded that Psephophorus, a close ally of Dermochelys, living in the Miocene, possessed a continuous plastron of mosaic-like pieces. If the latter view is held, we might properly inquire how it happens that nature is so vacillating regarding the needs of this animal.

We may well doubt, too, that there has been sufficient time granted the Dermochelyidæ in which to effect the change in their armor. Case derives the family from Lytoloma, of the upper Cretaceous and lower Eocene ; but both Eosphargis and Psephophorus had appeared already in the Eocene. This implies rapid modifications of structure. On the other hand, it is evident that changes go on in the turtles very slowly. How much progress in the reduction of the carapace and plastron, for instance, has been effected in the Cheloniidæ since Cretaceous times?

A difficulty affecting not only Baur's later view, but also the earlier one, is experienced in endeavoring to understand what advantage Dermochelys has gained over the alleged old-fashioned turtles by undergoing its various supposed adaptive changes. The thecophore sea turtles are more numerous in genera, species, and individuals than the Athecæ, notwithstanding the fact that the former have been relentlessly pursued for their flesh, their shell, and their eggs. As an ancient, intractable form, with difficulty adapting itself to its environment, we can understand Dermochelys.

Seeley ${ }^{1}$ has felt the necessity of accounting for the origin of the armor of turtles in a way different from that usually adopted. He thought that a portion of the carapace had its 1 Quar. Journ. Geol. Soc., vol. xxxvi, p. 410. London, I880. 
origin in bone developed, not in, but beneath the skin; and he suggested that the uncinate processes of the ribs of the crocodiles and birds might afford a clue to the solution of the problem. However, these uncinate processes are of cartilaginous origin, while the bony plates which constitute the greater portion of the carapace are of membranous origin.

We must recognize, at least in the Amniota, besides the bones developed from a basis of cartilage, two kinds of membrane bone. One of these is developed within the external integument itself; the other in the fasciæ, beneath the skin. Examples of the first kind, or true dermal bones, may be found in the osteodermal plates which occur in the scales of the Scincidæ and of some other lizards. Such, too, are the pieces which form the mosaic armor of Dermochelys. Examples of the second kind of bones, or fascia bones, are furnished by the so-called abdominal ribs of Sphenodon. Of course the two kinds may often coalesce with each other or with cartilage bones.

In the abdomen of the cayman both strata of bones occur. There is a set of abdominal ribs developed in the subcutaneous fascia, while in the skin itself there is a system of bony scutes which constitute a ventral armor. Sphenodon likewise possesses a system of abdominal ribs, which are wholly independent of the true ribs; but there is no dermal armor. If bony plates were developed in the ventral scales of Sphenodon, we would find two strata of bones, as in the cayman.

The abdominal ribs of Sphenodon, then, are homologous with those of the cayman, and not with the latter's dermal armor. It is generally agreed that most of the plastral bones of the turtles find their equivalents in the abdominal ribs of Sphenodon, not in the dermal armor of the cayman. The epiplastra and the entoplastron of the Testudines are doubtless the homologues of the clavicle and the interclavicle of other reptiles and of the Stegocephali, and belong to the same stratum of bone as the abdominal ribs.

Now it seems to me almost certain that the marginal bones of turtles have had the same origin as the bones of the plastron; that is, they are not dermal bones, but fascia bones. Further- 
more, I see no reason why we may not regard the nuchal bone and those plates of bone which have united with the neural spines to form the neuralia, and with the ribs to form the costalia, as having originated in the same way. Two strata of bones might as reasonably be expected to occur on the dorsal region of the body as on the ventral. In accounting for the condition of the carapaces of modern turtles, we may suppose that the earliest ancestors of turtles had a scaly skin, which contained osteodermal plates. ${ }^{1}$ Beneath these there were developed first, perhaps, in the fascia of the shoulders, a nuchal bone, later other plates which in time became transformed into the neuralia and costalia. As these deeper-seated fascia bones increased in importance, the osteodermal plates underwent gradual reduction. Only in Dermochelys have they maintained anything like their early importance. As regards the deeper layer of bones even in this turtle, the ribs, flattened, and with jagged edges, seem to me to indicate that at some time in the remote past there have been costal plates of membrane bone fused with them.

Can we find any evidences bearing on the hypothesis proposed?

In Vol. iv of the University Geological Survey of Kansas, pp. 370 et seq., Case has described and given figures of three species of the genus Toxochelys, not uncommon turtles of the upper Cretaceous deposits of Kansas. While working in Dr. Baur's laboratory in the University of Chicago, I had the privilege of studying and of making drawings of the specimen of $T$. serrifer, which Case has presented on his Pl. LXXXIII. This specimen is the property of the paleontological department of the University of Kansas, now in charge of Dr. S. W. Williston. One of the most interesting observations that resulted, one that has often been recalled to mind, was that there

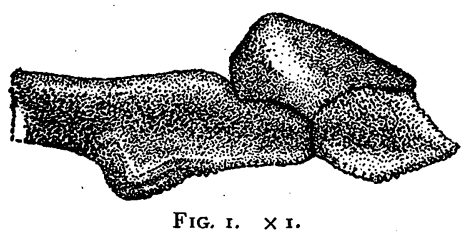
was evidently a series of separate bones along the middle of the back, lying across certain of the articulations between neurals.

${ }^{1}$ Baur, G. Biol. Centralblatt, Bd. ix, p. I82; Sci., vol. xi, p. I44. 
Case has figured one of them and referred to it in his description on page 382. He has, however, scarcely done it justice when he refers to it as a thin ossicle. Fig. I, here presented, gives a lateral view of this ossicle and of the seventh and eighth neuralia on which it rests. The figure is of the size of the object.

The drawing that I made of the carapace, seen from above, is slightly differrent from that of Dr. Case, and I here reproduce such part of it as pertains to the bones involved (Fig. 2), one-

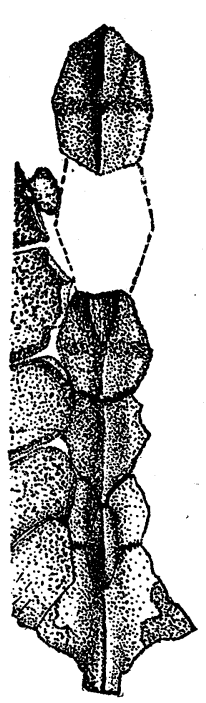

FIG. 2. $\times \frac{1}{2}$.

half natural size. It is my opinion that Case has made the fifth and sixth neuralia exchange places in his drawing. My reasons for so thinking are these: On the anterior end of neural 7 of Case's figure (9, according to his notation) there is an excavation that is not filled up as he has placed the bones; while as I have placed them, this excavation is accurately filled by a process from my neural 6. Again, Toxochelys evidently had, like its relatives, Thalassochelys and Chelydra, a system of epidermal scutes. Now, in these last-named genera, and in the great majority of other turtles, the suture impressions of these scutes cross the first, third, fifth, and eighth neuralia. The exceptions are rare. According to Owens's ${ }^{1}$ figure, the suture between the fourth and fifth scute passes across behind the eighth neural. Now, as I have arranged the neuralia, the dermal sutures are in their proper places. Another suture would probably cross just behind the ossicle lying across the suture, between neuralia 7 and 8 .

At the anterior end of neural 5 there is an excavation which had evidently served for the reception of an ossicle like the one across neurals 7 and 8 ; and in the collection there was then a bone like the ossicle referred to, and it quite accurately fitted the excavated surface. At that time there was no doubt that those bones belonged as they were drawn. There was also in the collection another bone, which I have figured as the

1 Owen. Anat. Vert., vol. i, p. 6r. 
third neural. It has, as it should have, an epidermal sutural impression across it. On the anterior end of this bone there was present a prominent tubercle, which in form and position resembled the distinct ossicles further behind; but there was no suture at its base. The conclusion drawn was that it was once distinct but had become coössified with the underlying neural.

Fig. 3 represents, of actual size, another bone that was found in the same collection of Toxochelys materials. Its upper portion resembled closely one of the ossicles described above; but below this there was a thinner portion, which had evidently been buried in the flesh. It was regarded as equivalent to one of the rows of bones which are to be found along the upper edge of the tail of Chelydra.

It seems to me' evident, therefore, that

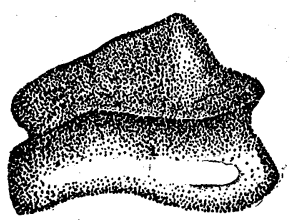

FIG. 3. $\times$ I. that row of tubercular ossicles along the back of Toxochelys was simply a continuation forward of the row that, like those of Chelydra, must have been present on the tail. These last must be reckoned as of purely dermal origin; so, too, must those on the carapace. Moreover, the neuralia on which they were reposing must belong to a deeper stratum of bone.

A median keel along the back is a not uncommon feature of turtles. Nearly all species possess it at an early stage of life ; although it may become obsolete as growth proceeds. In some tortoises this keel is elevated at intervals into prominent tubercles. These occur near the hinder border of each of the median bony scutes. And that is just where those tubercle-like ossicles of Toxochelys were found. I conclude, therefore, that these dorsal tubercles of our existing turtles have originated from a median dorsal row of dermal bones, distinct in the earlier forms, but now ossifying continuously with the underlying neurals. In the young of the diamond-back terrapin (Malaclemys terrapin) these dorsal tubercles are greatly developed and consist of four or five globular masses like small peas. It would be interesting to have their development studied, in order to ascertain if possibly they may yet possess distinct centres of ossification. 
If we examine the carapace of a specimen of Dermochelys, or, in lieu thereof, the plates presented by Gervais, ${ }^{1}$ we shall find that along the mid-line of the dorsal surface there is a row of enlarged bony plates, each bearing on its upper surface a prominent ridge. If we suppose that the early ancestors of our common turtles had at once a carapace like that of Dermochelys and a more or less rudimentary carapace of the common kind, it will be easy to comprehend that, as the dermal carapace underwent reduction, some of the larger median plates remained behind, first as independent ossicles, then as mere knobs on the neuralia.

A further examination of the test of Dermochelys proves that on the upper surface there are six more keels, three on each side. The third keel on each side, reckoning from the mid-line, forms the margin of the carapace; the two others are between it and the median keel. Each of these ridges, or keels, is composed of polygonal bony plates considerably larger than those occupying the spaces between the keels.

In a considerable number of species of turtles there are to be found on the carapace three keels, a median and two lateral. The lateral keels, although usually not so prominent as the median keel, are sometimes quite as well developed, and are occasionally conspicuously tuberculated. The median and the lateral keels are to be seen in young individuals of the snapper (Chelydra), and are strikingly displayed in large specimens of the alligator snapper (Macroclemys). In the latter species the tubercles are very large and projecting. Other tricarinate species are Staurotypus triporcatus, ${ }^{2}$ Damonia reevesii, ${ }^{3}$ and Nicoria trijuga. ${ }^{4}$ These lateral keels occupy exactly the position held by the first pair of lateral keels of the carapace of Dermochelys ; and it seems to me entirely probable that they have been inherited from a common ancestor, and have been produced from rows of distinct ossicles, as the middle keel has.

A search among various genera of thecophore turtles for traces of the second pair of lateral keels, as seen in Dermo-

1 Nouv. Archives du Museum, vol. viii (1872), Pl. IX.

${ }^{2}$ Gray. Catalogue Shield Reptiles, pt. i, Pl. XX B.

${ }^{3}$ Op. cit., Pl. V.

4 Op. cit., Pl. IV. 
chelys, was less fruitful ; and I had about concluded that all vestiges of them had vanished. Finally, however, I was led to examine more closely the carapace of Macroclemys. These turtles alone among all living forms, so far as I know, possess a row of three or four epidermal scutes lying along each side between the costal scutes and the marginals. They are known as supramarginals. Each of these areas is lifted up into a rounded knob somewhat like the tubercles of the keels higher up. This row of knobs I regard as the last remaining vestiges in the Thecophora, of the second pair of keels of the ancestral turtle. This pair of keels in Dermochelys may properly be called the supramarginal keels.

As to the third pair of lateral keels, they have probably left traces of themselves in the serrations that mark the margins of the carapace of many turtles, more especially the posterior margins.

The ventral surface of Dermochelys is provided with five keels, two lateral on each side and a median. The two lateral pairs are most conspicuously developed in a young Dermochelys recently hatched. These keels, both dorsal and ventral, may be of some use in swimming, in maintaining the body in a direct course; but the adults of other sea turtles are without more than the merest traces of them. Nevertheless, some of the ventral keels are well developed in the young of the marine turtles. In a young Thalassochelys ${ }^{1}$ the first pair of lateral keels runs along the middle of the hyo- and hypoplastral bones, and these keels are conspicuously tuberculated. In the same individual the keels of the second pair are seen to run along the rows of inframarginals and are also tuberculated. Relatively few turtles possess inframarginals, and it was the finding of the lateral keels in Thalassochelys that suggested to me an examination of the supramarginals of Macroclemys in my search for traces of the corresponding keels on the upper surface of the body.

The plastron of Toxochelys possesses on each side a low but sharply defined keel, which corresponds to one of the first pair of Dermochelys. It is represented in Case's figure. We should

1 Agassiz, A. Cont. Nat. Hist., N. A., vol. ii, Pl. V, Figs. 14-16. 
hardly expect a huge sea turtle like Protostega to possess a pair of plastral keels ; but that such were present may be seen from the examination of my figures of this plastron. ${ }^{1}$ A few turtles which are fitted for existence on the land also have these keels. They may be seen in Gray's figures of Kachuga lineata and $K$. dhongoka. ${ }^{2}$ I find no tubercles that furnish evidences of remains of the median ventral keel in any turtles except Dermochelys. This keel appears to have quite completely vanished. I shall, however, return to a consideration of it. All the keels, as we now find them in the Thecophora, I look upon as having originated through the fusion of rows of distinct dermal ossicles with the underlying bones of the carapace and plastron.

The presence, in turtles of so many and so widely removed families, of these keels and rudiments thereof, always more or less tuberculated at an early stage of life, is rendered comprehensible if we once admit that the common ancestors of the groups possessed corresponding rows of tuberculated bones. On the other hand, the possession of these numerous keels by Dermochelys is, we might say, incomprehensible if we are to suppose that it took its origin from a race of sea turtles that had completely, or nearly completely, lost the carapace and plastron. If the structure of the new carapace had anything to do with that of the old one, and if the keels of the superior second lateral pair were really associated with the supramarginal scutes, how could these keels have reappeared in Dermochelys if this were derived from a stock which had no supramarginals or supramarginal keels? If the disposition of the new carapace had nothing to do with that of the old, how came it that we can seem to find such close correspondences? Dermochelys would offer a most remarkable case of convergence or reversion.

One of the most remarkable facts about turtles is the want of correspondence between the horny scutes of the carapace and plastron and the bones which underlie them. When osteodermal plates are developed in the crocodiles and lizards, they are overlain by corresponding horny scutes. In tortoises, on the contrary, each lateral horny scute of the carapace covers a

1 Field Columbian Museum Pubs., Zool., vol. i, Pls. IV, V.

2 Catalogue Shield Reptiles, pt. i, Pls. XVII, XVIII. 
costal plate, the half of the plate next in front, and the half of the plate next behind. The neural scutes are similarly disposed, covering sometimes wholes or parts of from two to four neurals. The marginal scutes are only as long as the marginal bones which they cover; but, instead of coinciding with the latter, they "break joints" with them. Neither do the plastral scutes coincide with the bones of the plastron. It is evident that the scutes have had a development wholly independent of the bones beneath them. How has this occurred?

The skin of the adult Dermochelys is wholly devoid of division into areas resembling scales or scutes; but in the young, a fine specimen of which I have been permitted to examine in the National Museum, the skin is everywhere, on body and limbs, broken up into small polygonal areas. Along the dorsal and ventral keels these areas are considerably larger than elsewhere. It is quite certain that these areas coincide with the osteodermal plates which are, or will be, developed in the skin. When the bony plates have increased in size, the overlying scute has become correspondingly extended.

I conclude, therefore, that the earliest turtles were covered with numerous small horny scales, possibly overlapping like those of lizards; and that in the dermis beneath these scales there were produced osteodermal plates. From such an ancestor, land-inhabiting, and having limbs fitted for such a life, there arose a race that has culminated in our leather-back turtle. This race early betook itself to an aquatic life, and its limbs suffered profound modifications. Possibly also the epidermal structures and the underlying bony plates became more or less modified. Quite certainly the deeper carapace and plastron underwent considerable reduction. The nuchal bone, however, remains to the present day.

From the same primitive ancestors that gave birth to this athecate tribe there arose another vigorous race, whose members tarried longer on land. In the members of this branch of the Testudines the elements of the more deeply developed shield were probably present, but in a somewhat rudimentary state. To such an animal, with probably a broad and inflexible body, slow of movement, and with few defenses, it would have 
been advantageous to have a more resistant armor than that afforded by a layer of small articulated dermal bones. Fewer and larger bones, resting on and perhaps breaking joints with the as yet perhaps rather indifferently developed fascia bones, would have rendered the shield less vulnerable. It was only natural that the osteodermal plates of the already present keels, and indeed only a few of these plates, should grow at the expense of the smaller surrounding plates. As these few plates extended themselves at their base, they rose above the surface in the form of tubercles or spines. Possibly it was their function as spines that determined their growth. The result was finally, as I view the matter now, that one of these plates, with its correspondingly extended epidermal scute, occupied most of the space now covered by each of the scutes of our living turtles. At length the deeper elements of the carapace and plastron attained such a stage of development that the dermal bones were of small service, and they began to undergo reduction; but this reduction did not necessarily interfere with the subsequent growth of the epidermal scute. In some cases the extirpation of outlying isolated patches of horny epidermis is not yet complete, as may be seen on the plastron of Chelydra. As already suggested, not only have the keels disappeared from many turtles, but in many cases even the epidermal scutes, which became associated with the ossicles of those keels. The supramarginals have disappeared from all except Macroclemys. The Cheloniidæ possess inframarginals; so, too, does Dermatemys. Staurotypus triporcatus ${ }^{1}$ has a row of only two inframarginal scutes lying across its shortened bridge. In most genera the pectoral and abdominal scutes have come into contact with the marginals. There are, then, often found at each side of the bridge a scute, the axillary and the inguinal. These are doubtless vestiges of the inframarginal keels.

That the epidermal scutes have originally taken their start from the individual tubercles of the various keels, may be seen on examination of the scutes in almost any of our turtles, more especially the lower forms, Chelydra, Malaclemys, etc. In the

1 Gray. Catalogue Shield Reptiles, pt. i, Pl. XX B. 
neural scutes the lines of growth show that the tubercle at the posterior border is the starting point ; and from there the scute spreads mostly forward and laterally. In the costal scutes the growth begins near the upper hinder angle and spreads downward and forward. If there is a lateral keel, its tubercles form the starting point. From these the scutes have spread toward the marginals, and between the former and the latter the supramarginals have been suppressed. It might be supposed that the manner in which the epidermal scutes extend themselves is determined by the growth of the underlying bones; but a study of the relations of the two sets of structures will, I think, disprove this idea. These scutes are simply following the course laid down by their predecessors. In some of the higher turtles, as species of Testudo, the centre of growth, the areola, of some of the scutes has moved nearer the centre of the scute.

The great scutes of the plastron all grow from a point near the posterior outer angle forward and toward the mid-line where they have met. In doing this they have suppressed the scutes of the middle keel. To a less extent they have grown upward and forward, and have thereby suppressed partially or wholly the inframarginals.

If the reader will examine the figures on Pls. XXII-XXV, of Gray's Catalogue of Shield Reptiles, Pt. i, and Pl. VI of Boulenger's Catalogue of Chelonians, he will find a large scute on the mid-line of the plastron of each of the turtles there depicted, near the anterior end, and, except on Pl. XXIII, surrounded by other scutes. This is the intergular. It occupies the position where the median and first pair of lateral keels of Dermochelys come together. Indeed, it is located rather on the territory where the median keel would end anteriorly. Its lines of growth show that it spreads from a central point in all directions. This intergular has very much the appearance of having originated from the median plastral keel. Usually the intergular extends forward to the anterior margin of the plastron and is smaller, as in Gray's Catalogue, Pls. XXVII, XXVIII (Podocnemis). In such cases it less forcibly suggests an origin from the median keel, and has evidently undergone great reduction. 
An inspection of the plastron of the alligator snapper (Macroclemys), or of the figures on page 26 of Boulenger's Catalogue of Chelonians, shows that in this genus there is sometimes present an intergular shield. This remarkable turtle, then, has vertebral, costal, supramarginal, marginal, and inframarginal shields, a row consisting of the usual plastral shields, and occasionally an intergular, that is, rows of epidermal shields representing all twelve of the longitudinal keels of Dermochelys and, as I believe, of the ancestors of all the groups of turtles. So far as I know, there is no other turtle which shows all these. The marine turtles are not far behind, since they present traces of all the keels, except the supramarginals.

The number of epidermal shields and of the hypothetical osteodermal plates belonging to each keel of the thecophorous turtles is, of course, much smaller than in Dermochelys, about one in each keel of the carapace for two vertebræ and pairs of ribs. An examination of the bony plates which form the armor of the sturgeon reveals some characters in common with those which we suppose once belonged to the turtles. They are broadbased, rise into a backwardly directed spine, and in number are about one-half as many as the ribs and vertebræ which underlie them. On the tail of Chelydra, a cousin of Toxochelys, the dermal bones which produce the serrations of that tail fall in number considerably below the vertebræ on which they rest.

Reflection on the early state of the Chelonian armor has led me to study the condition of corresponding structures in Sphenodon, that reptile whose position lies so close to the base of the reptilian stem.

Many reptiles, as is well known, possess longitudinal rows of enlarged scales, especially one which forms a crest along the dorsal mid-line ; and it occurred to me that possibly Sphenodon would show not only this but traces of other keels. What I find is as follows: On the dorsum of the tail there is a row of quite large horny tubercles, which resemble quite closely those seen on the tail of Chelydra. In none of them, however, do I find ossifications. ${ }^{1}$ If any such have ever been present, they

1 Günther, A. Philos. Trans. Roy. Soc., vol. clvii (1867). 
vanished long ago. Lvoff, however, states $^{1}$ that he has found minute ossifications in the teeth of the crest of Sphenodon. This row of tubercles is continued forward to the head, with one or two interruptions, by a series of thin horny plates.

On each side of the tail are evidences of two other keels. Of these, the upper appears to occupy the position of the costal keel of the turtles; the other the position of the marginal keels. On the trunk I find no satisfactory evidences of the existence of lateral keels, although there are some scattered enlarged scales. On the rump I find a rather interesting thing, although it may have no significance. On each side is a row of pointed scales, about six in number, which begins near the upper end of the ilium and runs backward and toward the median crest. These two rows of scales suggest the hinder borders of the carapace of Dermochelys.

A dissection of the tail of Sphenodon proves that there is just one horny tubercle on its dorsum for each neural spine. Between the bases of adjacent tubercles folds begin and run downward on each side across the tail; on the under side of the tail there are, between the successive folds mentioned, two transverse rows of enlarged scales. On the sides of the tail the epidermal scales are much smaller and more numerous.

On the belly the epidermal scales resemble those found on the under side of the tail. On the side of the trunk they are again very small. A careful reflection of the skin of the belly brings to light the "abdominal ribs," or gastralia, as they have been called by Baur. Immediately behind the sternum the skin is loosely attached to them; but along most of the belly it is closely adherent. There are about twenty-five of these gastralia. ${ }^{2}$ Each may be said to resemble a very open capital V, with the apex directed forward. Each consists of three closely united bones; one forming the apex of the $\mathrm{V}$ and a portion of its sides, the other two forming the extremities of the sides of the $\mathrm{V}$ : Now, there is a cross row of epidermal scales for each of these gastralia, and two of the latter for each pair of ribs. In fact, the lower ends of the ribs are attached to alternate

1 Lvoff, W. Bull. Soc. Imp. Natur. Moscou, vol. 1x, pt. ii, p. 333.

2 Günther, A., loc. cit. 
gastralia. In crocodiles the gastralia are only equal in number to the pairs of ribs in the same region of the body. The cross rows of epidermal scutes also equal the ribs in number, but they do not follow the direction taken by the gastralia, as they do approximately in Sphenodon. In snakes the rows of epidermal scales equal the ribs. In general, a study of the scales of reptiles would, I think, show that originally, at least, there has been some simple numerical ratio between the segments of the body and the number of gastralia and epidermal scales.

Gastralia of the form described have occurred not rarely in the vertebrates of past ages. They occurred in Archegosaurus and other genera among the Stegocephali, and in the Ichthyosauria, the Sauropterygia, and the Pterosauria among the extinct reptiles. Being so widely distributed among the early reptiles, some of the latter showing relationships in some respects with turtles, it is very probable that the ancestors of the latter possessed similar gastralia. Whether there were several of these for each pair of ribs, as was the case with the Stegocephali, or two, as in Sphenodon, or one, as in Ichthyosaurus, we cannot tell.

Assuming that the plastron of turtles has had its origin in such gastralia, it would be interesting to know how many of these have been concerned in its construction. From the great length of the plastron in most turtles, and the slender form of the gastralia, we might at first suppose that many were involved; but this, I think, would be an erroneous conclusion. We must recollect that turtles possess only ten dorsal and no lumbar vertebræ. Hence not more gastralia can be included than those corresponding to ten pairs of ribs; indeed, not so many.

The umbilicus in young turtles is placed where the suture between the hyoplastra and hypoplastra crosses the mid-line; hence this suture is an approximately fixed line. It corresponds pretty closely to the suture between the fourth and the fifth ribs. Therefore, four pairs of ribs belong in front of it ; six pairs behind it. Of the four pairs in front of these sutures, we must, it seems likely, concede that at least two originally were connected with the sternum below, and hence would not 
have corresponding gastralia. There could then not have been more gastralia than would correspond to two pairs of ribs. Excluding the entoplastron and epiplastra, which originated otherwise, we have in front of the umbilicus, in most turtles, a single pair of plastral elements, the hyoplastra. But it is evident that in the earliest turtles there was an additional pair, the mesoplastrals. They are present in some living Pleurodira. In the genus Sternothærus ${ }^{1}$ the mesoplastrals extend right across the plastron, and meet in the mid-line. In Pelomedusa ${ }^{2}$ and Podocnemis ${ }^{3}$ they are reduced to the condition of wedgeshaped plates lying on the bridge. In all the Cryptodira and the Trionychia these plates have been extirpated. If, then, we have not assigned too many pairs of ribs to the sternal region, there was originally involved in the preumbilical region the gastralia belonging to only two pairs of ribs, those of a pair of ribs for each pair of plastral elements.

It is possible that six sets of gastralia entered into the composition of the hypoplastra and xiphiplastra. However, we do not find, in Sphenodon or any other forms, that the pubic region is covered with gastralia. In Sphenodon there are three lumbar vertebræ, and some of the hindermost gastralia are much reduced in extent. If the plastron of most turtles extends beneath the pelvic region and even behind it, this is due doubtless to secondary modifications. The condition of the plastron of the Chelydridæ is probably more primitive. We must therefore believe that some of the hindermost gastralia become aborted. I am inclined to the opinion that we have at present in the hinder portion of the plastron elements representing only two pairs of ribs. If the hyoplastra and the mesoplastra each were developed from the gastralia belonging to a single pair of ribs, the same thing appears probable in the case 'of the hinder plastral elements. Otherwise we must assume that there has been coössification of originally distinct bones; but the manner in which the mesoplastra have been thrust out of the plastron in most turtles indicates that here

1 Boulenger. Cat. of Chelonians, p. 193, Fig. 47.

2 Op. cit., p. 199, Fig. 49.

3 Op. cit., p. $20 \mathrm{I}$, Fig. $5 \mathrm{I}$. 
there is not much tendency toward coössification. This view is borne out by the suppression of the entoplastron in Dermochelys and the Cinosternidæ. For the same reason, and because the Ichthyosauria and the Plesiosauria seem to have possessed only one set of gastralia for each pair of ribs, I am inclined to believe that such was the condition in turtles. It appears that from the Stegocephali upward there has been a tendency toward a reduction in the number of sets of gastralia belonging to each body segment. If later on in the history of turtles certain plastral elements were excluded from the hinder portion of the plastron, as the mesoplastra have in most turtles been excluded, we have no record of the fact. If, then, our surmises are correct, the plastron of most of our turtles consists of the interclavicle, the clavicles, and elements derived from the gastralia corresponding to three pairs of ribs.

In turtles, it will be recalled, the plastral elements of the right and left sides are always distinct. In all for a varying period of life there is in the centre of the plastron a large fontanelle. In some, as Chelydra and the sea turtles, the fontanelle persists through life, or at least until a late period. We are safe in assuming that its existence is a primitive condition. On the other hand, in Sphenodon and in many of the extinct reptiles which possess gastralia, the median element is continuous across the mid-line of the abdomen. It seems therefore probable that the plastral bones of turtles, except clavicles and interclavicle, have been derived from the lateral elements of the primitive gastralia, while the median element has become aborted. I do not overlook the fact that in the crocodiles two distinct bones represent the median element found in the gastralia of Sphenodon. Even in the crocodiles, however, these bones are smaller than are those which lie farther from the mid-line.

U. S. Nat. Museum,

October $10,1898$. 